\title{
The Effect of a Federal Controlled Substance Act Schedule Change on Hydrocodone Combination Products Claims in a Medicaid Population
}

\author{
Stephanie Tran, PharmD; Pavel Lavitas, PharmD, BCPS; Karen Stevens, PharmD; \\ Bonnie C. Greenwood, PharmD, BCPS; Karen Clements, ScD; Caroline J. Alper, MD; \\ Kimberly Lenz, PharmD; Mylissa Price, MPH, RPh; Tasmina Hydery, PharmD, MBA, CGP; \\ Jennifer L. Arnold, MS; Mito Takeshita, PharmD; Rachel Bacon, PharmD; \\ Justin P. Peristere, RPh; and Paul L. Jeffrey, PharmD
}

\begin{abstract}
BACKGROUND: In 2012, hydrocodone combination products (HCPs) were the most prescribed medications in the United States. Under the Controlled Substance Act of 1970, hydrocodone alone was classified as a Schedule II drug, while HCPs were classified as Schedule III, indicating a lower risk for abuse and misuse. However, according to a Drug Enforcement Agency analysis, the addition of nonopioids has not been shown to diminish abuse potential of hydrocodone. In response to concerns for drug abuse and overdose, the Drug Enforcement Agency rescheduled HCPs to Schedule II in October 2014, with the intent of limiting overprescribing and increasing awareness of their abuse potential. However, it is unknown whether this has affected the overall claims for HCPs in a Medicaid population.
\end{abstract}

OBJECTIVES: To (a) compare the trend in HCP prescription claims with select non-HCP (opioid and nonopioid) analgesic claims before and after the HCP schedule change in the Massachusetts Medicaid fee-for-service/ Primary Care Clinician plan population and (b) identify if there was a change in HCP new start member and claim characteristics before and after the HCP schedule change.

METHODS: This quasi-experimental, retrospective study used enrollment and pharmacy claims data to evaluate all members in the study population 1 year before and after the HCP schedule change. The number of claims for HCPs and select non-HCP analgesics was reported as the monthly rate per total population, and an interrupted time series analysis compared the change in the monthly rate of claims across groups. Members with 1 or more pharmacy claims for a new HCP prescription during a 5-month period before or after the HCP schedule change were analyzed to determine member demographics (age, gender, and number of claims) and claim characteristics (average daily dose, average quantity per claim, and days supply).

RESULTS: The rate of HCP claims increased before and decreased after the HCP schedule change. Controlling for the trend during the period before the HCP schedule change, the rate of HCP claims per 1,000 members per month decreased at a greater rate than non-HCP analgesics in the period after the HCP schedule change $(P<0.001)$. The percentage of HCP claims for new start members decreased after the HCP schedule change $(44.9 \%$ vs. $34.1 \%$ of all HCP claims pre- to post-schedule change; $P<0.001$ ). In the group of new starts, there was not a significant difference in the average daily dose ( $26.3 \mathrm{mg}$ vs. $26.4 \mathrm{mg} ; P=0.69$ ), while there was a decrease in average number of tablets dispensed per claim (from 37.1 to 20.3 tablets; $P<0.001)$ and an increase in the percentage of claims for a shorter days supply (from $57.7 \%$ to $81.6 \% ; P<0.001$ ).

CONCLUSIONS: The findings of this study suggest that the HCP schedule change may have contributed to the decrease in claims for HCPs in a Medicaid population. After the HCP schedule change, there was a trend towards decreased HCP use among new starts.

J Manag Care Spec Pharm. 2017;23(5):532-39

Copyright $\odot 2017$, Academy of Managed Care Pharmacy. All rights reserved.

\section{What is already known about this subject}

Hydrocodone combination products (HCPs) have a high potential for abuse and misuse and are frequently prescribed for the treatment of moderate to moderately severe pain.

According to the Drug Enforcement Administration's final rule, HCPs, which were previously Schedule III medications, were reclassified as Schedule II medications on October 6, 2014

\section{What this study adds}

This study showed that claims for HCPs decreased after the HCP schedule change without a corresponding increase in claims for non-HCP analgesics in a Medicaid population.

After the HCP schedule change, claims for new starts showed a decrease in average number of tablets per claim and an increase in percentage of claims for a shorter days supply.

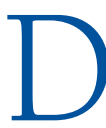
ata from the Centers for Disease Control and Prevention (CDC) show that increased numbers of opioid prescriptions are directly correlated with an alarming increase in deaths from opioid overdose. ${ }^{1}$ The CDC reports that every day in the United States 46 people die as a result of prescription pain reliever overdose and that, in 2013, drug overdoses were the leading cause of death due to injury. ${ }^{2}$ In 2014, National Institute on Drug Abuse (NIDA) of the National Institutes of Health (NIH) testimony to Congress regarding prescription pain relievers noted that opioids have a high potential for abuse, which could lead to severe psychological or physical dependence. ${ }^{3}$ Furthermore, the NIDA stated that the greater availability of opioids has been associated with increases in abuse of these substances by patients and other unintended users who diverted these substances for nonmedical use. ${ }^{3}$

When Congress passed the Controlled Substance Act in 1970, hydrocodone combination products (HCPs) were classified as Schedule III drugs, while hydrocodone alone was classified as Schedule II. ${ }^{4}$ The Drug Enforcement Administration (DEA) classifies drugs based on potential for abuse, currently accepted medical use in the United States, and the degree of dependence. Substances classified as Schedule III are considered to have less potential for abuse than substances classified 
as Schedule I or II. ${ }^{5}$ HCPs contain hydrocodone in combination with 1 or more therapeutically active nonopioid ingredients (such as acetaminophen or ibuprofen), are approved by the U.S. Food and Drug Administration (FDA) for the treatment of moderate to moderately severe pain, and are intended to be used as needed for treatment of acute pain. ${ }^{6}$ Notably, according to an analysis by the DEA, the addition of nonopioid substances, such as acetaminophen, has not been shown to diminish the abuse potential of hydrocodone. ${ }^{7}$ In 2012, over 135 million HCP prescriptions were dispensed, making them the most widely dispensed agents in the United States. The volume was nearly $25 \%$ greater than the second top-ranked medication, levothyroxine, and about $50 \%$ greater than lisinopril, the third-ranked medication. ${ }^{6}$ The high use of hydrocodone is correlated with safety concerns, since a 2011 report cites that approximately 97,000 drug-related emergency room visits may be attributed to the abuse and misuse of hydrocodone products. ${ }^{8}$

In light of the increasing concerns for HCP overuse and overdose risk, the DEA, in its final rule regarding the rescheduling of HCPs, reclassified all HCPs as Schedule II medications effective October 6, 2014. ${ }^{9}$ Refills are not allowed for Schedule II medications, whereas Schedule III medications may be refilled up to 5 times within 6 months from the date that a prescription was written..$^{10}$ The intent of reclassifying HCPs to Schedule II was to curb overprescribing and inform prescribers of the abuse potential of HCPs. Two published studies have examined the effect of the schedule change on HCP prescribing. One found a decline in HCP prescribing after the schedule change, while the second found a decrease in HCP use and an increase in use of less restricted analgesics. ${ }^{11,12}$ It is possible that an unintended effect of the HCP schedule change is that instead of prescribing less medication, prescribers will shift towards Schedule III or other less restricted analgesics for the treatment of pain.

To our knowledge, no studies have evaluated the effect of the HCP schedule change on a Medicaid population. Compared with individuals with private insurance, the prevalence of opioid abuse is estimated to be over 10 times higher among Medicaid enrollees. ${ }^{13}$ This may be because the Medicaid population is generally associated with a lower health status and higher rate of mental disorders than private insurance enrollees. ${ }^{14,15}$ Thus, there is a compelling need to evaluate the effect of a federal schedule change on this population. The primary aim of this study was to evaluate the effect of the federal controlled substance schedule change on prescribing patterns by comparing trends in HCP and non-HCP analgesic claims before and after the HCP schedule change in the Massachusetts Medicaid fee-for-service/Primary Care Clinician (FFS/PCC) plan population. Our secondary aim was to identify if there was a change in HCP new start member and claim characteristics before and after the HCP schedule change.

\section{Methods}

\section{Design, Data Source, and Sample Selection}

This quasi-experimental study used enrollment and pharmacy claims data from the Massachusetts Medicaid pharmacy claims processing system. The study was approved by the University of Massachusetts Medical School Institutional Review Board before study initiation.

Members who were aged 18 years or older and enrolled in the FFS/PCC plan between November 1, 2013, and September 30,2015 , were included in the primary analysis. The HCP new start analysis included members enrolled in the FFS/PCC plan with 1 or more HCP claims during a 5-month period before (November 1, 2013-March 31, 2014) or after (May 1, 2015-September 30, 2015) the HCP schedule change. Members were excluded if they could not be linked to enrollment data, had Medicaid as a secondary insurance, did not have continuous enrollment before and after the change periods plus the preceding 6 months for each time period, or had inconsistent data (e.g., multiple date of births or gender listed). Finally, to ensure that chronic HCP users were excluded from the final population, members were excluded if they had 1 or more claims for any HCP in the 6 months before the first HCP claim.

This analysis focused on new HCP members because it was felt that members receiving chronic therapy would be less likely to be affected by the schedule change. The dates of the pre-HCP schedule change period were chosen to minimize the effect of anticipatory prescribing changes in the months leading up to the October 6, 2014 schedule change, while the dates of the post-HCP schedule change period were chosen to account for the allowance of existing HCP refills through April 8, 2015.

\section{Measures}

Primary Analysis. In order to compare the number of claims for HCPs with those of non-HCP analgesics during the study period, pharmacy claims data were extracted from the pharmacy claims processing system using generic sequence numbers (GSNs). Total Medicaid enrollment was identified on a monthly basis for the same time period.

Claims were categorized into 5 comparator groups: HCPs, other Schedule II analgesics, Schedule III analgesics, tramadol, and nonscheduled analgesics (Appendix, available in the online article). Tramadol was examined separately because of the DEA's 2014 final rule regarding the placement of tramadol into Schedule IV and high use based on an internal drug utilization review. ${ }^{16}$ Non-Schedule II analgesic combination products that contain acetaminophen or nonsteroidal antiinflammatory drugs were excluded because these medications may be prescribed for indications other than chronic pain (e.g., over-the-counter and prescription cough and cold products and medications intended to treat migraines). For each comparator arm, the total number of monthly claims was 


\section{FIGURE 1 Trend in HCP Claims Compared with Non-HCP Analgesic Claims Before and} After the HCP Schedule Change

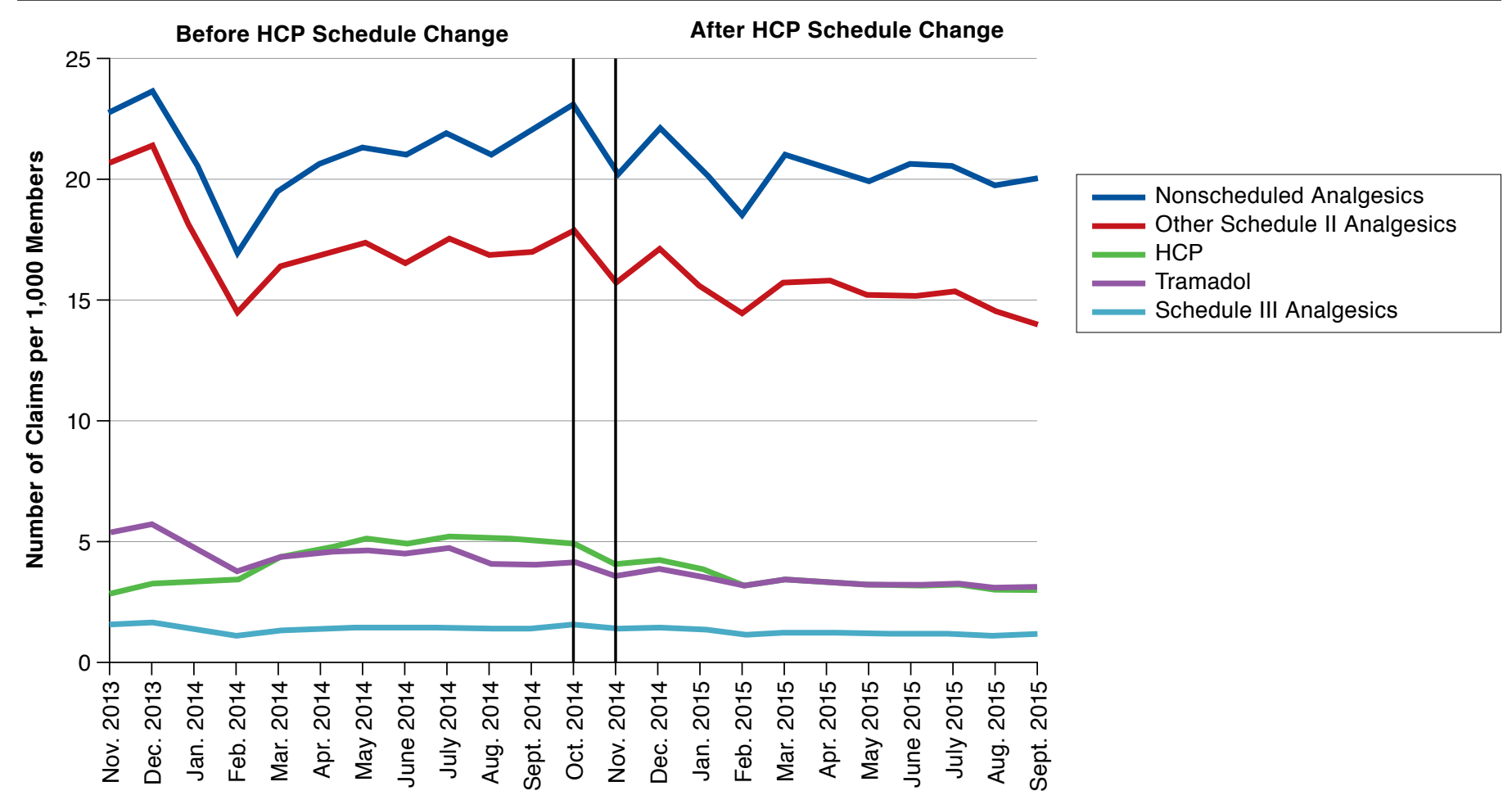

HCP = hydrocodone combination product.

divided by the total number of Medicaid members each month to derive the rate of claims per 1,000 members. Although the days supply varied from claim to claim, the maximum days supply was limited to 30 days in this population. Because the HCP schedule change was implemented on October 6, 2014, the month of October 2014 was excluded from the analysis.

HCP New Start Analysis. The number of HCP claims from November 1, 2013, to March 31, 2014 (pre-HCP schedule change) and May 1, 2015, to September 30, 2015 (post-HCP schedule change) in the HCP new start population was compared with the number of HCP claims in the total Medicaid population for the same periods.

HCP new start characteristics included member age and gender, average daily hydrocodone dose per claim, average number of tablets dispensed per claim, and number of claims by days supply. Member age and gender were identified from claims data. Member age was categorized as 20-39 years, 40-59 years, and 60 years and older to be consistent with the CDC/National Center for Health Statistics reporting measures; a group was added to account for 18 and 19 year olds. ${ }^{17}$ Whenever members aged within the 5 -month periods before and after the HCP schedule change, the younger age was used in the analysis. Average daily hydrocodone dose was calculated by multiplying the paid quantity and hydrocodone dose for each claim and then dividing by days supply. The average number of tablets dispensed per claim was found by adding the quantity dispensed for all claims and dividing it by the total number of claims. Liquid formulations were excluded from this portion of the analysis.

\section{Statistical Analysis}

An interrupted time series was conducted to examine the effect of the HCP schedule change on the rate of monthly claims per 1,000 members before and after the HCP schedule change. The pre- and post-schedule change monthly rates of HCP claims per 1,000 members were compared using a segmentedregression model fit with a generalized estimating equation, assuming a Poisson distribution and autoregressive correlation structure. For member demographics and claim characteristics in the HCP new start analysis, the chi-square test was used to test for differences between discrete variables, and the t-test was used to test for differences between continuous variables. All statistical analyses were conducted using the SAS software version 9.3 (SAS Institute, Cary, NC). 


\section{FIGURE 2 Analysis of Enrollment in HCP New Starts}

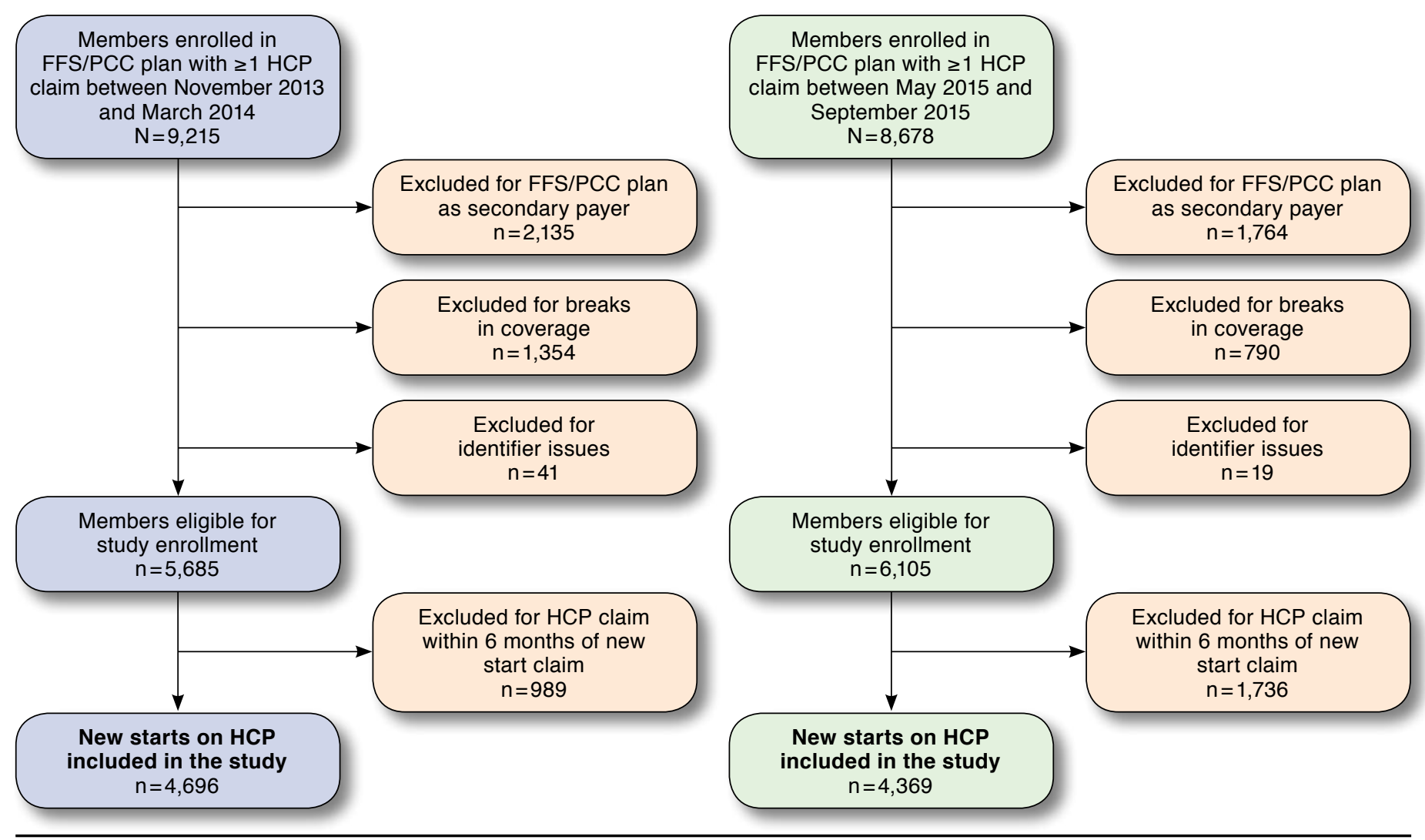

FFS/PCC =fee-for-service/Primary Care Clinician; HCP=hydrocodone combination product.

\section{Results}

\section{Primary Analysis}

The mean monthly member count for the FFS/PCC plan between November 1, 2013, and September 30, 2014 (before the HCP schedule change) was 972,198 members (range $=841,284$ $1,101,674$ ) and $1,011,968$ members (range $=923,489-1,165,059)$ between November 1, 2014, and September 30, 2015 (after the HCP schedule change).

During the year before the HCP schedule change, the rate of monthly HCP claims increased by 8.2 claims per 1,000 members per month, while the rate of claims for other Schedule II analgesics, Schedule III analgesics, tramadol, and nonscheduled analgesics decreased by 9.6, 0.1, 3.2, and 0.3 claims per 1,000 members per month, respectively. During the year after the HCP schedule change, the rate of HCP claims decreased by 141.9 claims per 1,000 members per month, while the rate of claims for other Schedule II analgesics, Schedule III analgesics, tramadol, and nonscheduled analgesics decreased by 231.6, $33.9,77.1$, and 154.8 claims per 1,000 members, respectively. Controlling for the trend during the pre-HCP schedule change period, the decrease in the rate of HCP claims per 1,000 members was greater than for non-HCP analgesics in the post-HCP schedule change period $(P<0.001$; Figure 1$)$.

\section{HCP New Start Analysis}

After application of exclusion criteria, 4,696 and 4,369 members had new start HCP claims in the pre- and post-HCP schedule change periods, respectively, and 19 members belonged to both study periods (Figure 2). With respect to HCP claims, 7,052 of $15,702(44.9 \%)$ claims in the pre-HCP schedule change period and 5,423 of 14,904 (36.4\%) claims in the post-HCP schedule change period were for new start members $(P<0.001)$.

Member Demographics. The age distribution of HCP new start members changed before and after the HCP schedule change, with a higher percentage of members aged 18-19 years and 20-39 years in the period after the HCP schedule change compared with the period before the HCP schedule change $(P<0.001)$. Female members received the majority of new HCP prescriptions in the pre- and post-HCP schedule change periods (68.6\% and $68.0 \%$, respectively; $P=0.51$; Table 1 ). 
TABLE 1

\begin{tabular}{|c|c|c|c|}
\hline & $\begin{array}{c}\text { Before HCP } \\
\text { Schedule Change } \\
\text { (November 2013- } \\
\text { March 2014) } \\
\mathbf{n}=4,696^{\mathrm{a}} \\
\mathrm{n}(\%)\end{array}$ & \begin{tabular}{|c} 
After HCP \\
Schedule Change \\
(May 2015- \\
September 2015) \\
$\mathbf{n}=4,369^{\mathrm{a}}$ \\
$\mathbf{n}(\%)$
\end{tabular} & $P$ Value \\
\hline \multicolumn{4}{|l|}{ Age groups (years) } \\
\hline $18-19$ & $216 \quad(4.6)$ & $306 \quad(7.0)$ & \multirow[t]{4}{*}{$<0.001$} \\
\hline $20-39$ & $1,810(38.5)$ & $1,954(44.7)$ & \\
\hline $40-59$ & $2,230 \quad(47.5)$ & $1,747(40.0)$ & \\
\hline$\geq 60$ & $440 \quad(9.4)$ & $362 \quad(8.3)$ & \\
\hline \multicolumn{4}{|l|}{ Gender } \\
\hline Male & $1,473 \quad(31.4)$ & $1,399(32.0)$ & \multirow[t]{2}{*}{0.510} \\
\hline Female & $3,223(68.6)$ & $2,970(68.0)$ & \\
\hline \multicolumn{4}{|c|}{ Number of Members by Total Claims During Study Period } \\
\hline 1 & $3,414(72.7)$ & $3,677(84.2)^{b}$ & \multirow[t]{3}{*}{$<0.001$} \\
\hline $2-5$ & $1,225(26.1)$ & $676(15.5)^{\mathrm{b}}$ & \\
\hline$\geq 6$ & $57 \quad(1.2)$ & $16 \quad(0.4)^{\mathrm{b}}$ & \\
\hline $\begin{array}{l}\text { Total number of claims } \\
\text { for all members }\end{array}$ & 7,052 & 5,423 & \\
\hline \multicolumn{4}{|c|}{$\begin{array}{l}\text { a Ninteen members belonged in the before and after HCP schedule change groups } \\
{ }^{b} \text { Total percentage does not add up to } 100 \% \text { due to rounding. } \\
\text { HCP = hydrocodone combination product. }\end{array}$} \\
\hline
\end{tabular}

Prescription Characteristics. There was not a significant difference in the average daily dose of hydrocodone for new start member claims in the periods before and after the HCP schedule change (26.3 mg vs. $26.4 \mathrm{mg}$; $P=0.69$; Table 2). The number of tablets dispensed per claim was greater in the period before the HCP schedule change compared with the period after the HCP schedule change (37.1 vs. 20.3; $P<0.001$; Table 2). The distribution of the number of claims per member changed preto post-HCP schedule change periods, with a higher percentage of members receiving only 1 claim after the HCP schedule change $(72.7 \%$ and $84.2 \%, P<0.001$, before and after the HCP schedule change, respectively; Table 1 ).

Between study periods, there was a difference in the distribution of days supply for new start HCP prescriptions $(P<0.001)$. In both periods, the majority of claims were for prescriptions written for 1-6 days supply. The percentage of prescriptions for 1-6 days supply increased pre- to post-HCP schedule change (57.7\%-81.6\%), while the percentage of prescriptions written for 7 or more days supply decreased (42.3\%18.4\%; Table 2).

\section{Discussion}

Short-acting opioids, such as HCPs, are effective for treating acute pain but should be avoided as the sole analgesic for the treatment of chronic pain. ${ }^{18}$ While this study does not examine whether HCPs in this Medicaid population were used as monotherapy for acute pain or as part of a combination regimen for chronic pain, it does show a decrease in the overall

\section{TABLE 2 HCP New Start Claim Characteristics}

\begin{tabular}{|c|c|c|c|}
\hline & \begin{tabular}{|c|} 
Before HCP \\
Schedule Change \\
(November 2013- \\
March 2014) \\
$\mathbf{n}=7,052$ \\
$\mathbf{n}(\%)$ \\
\end{tabular} & $\begin{array}{c}\text { After HCP } \\
\text { Schedule Change } \\
\text { (May 2015- } \\
\text { September 2015) } \\
\text { n }=5,423 \\
\text { n (\%) }\end{array}$ & $P$ Value \\
\hline $\begin{array}{l}\text { Average daily dose of } \\
\text { hydrocodone }(\mathrm{mg})\end{array}$ & $26.3(26.0-26.6)^{\mathrm{a}}$ & $26.4(26.1-26.7)^{\mathrm{a}}$ & 0.690 \\
\hline $\begin{array}{l}\text { Average number of tablets } \\
\text { dispensed per claim }\end{array}$ & $37.1(36.3-37.9)^{\mathrm{a}}$ & $20.3(19.8-20.8)^{a}$ & $<0.001$ \\
\hline \multicolumn{4}{|l|}{ Days supply } \\
\hline $1-6$ & $(57.7)$ & (81.6) & \multirow[t]{4}{*}{$<0.001$} \\
\hline $7-13$ & $941 \quad(13.3)$ & $558 \quad(10.3)$ & \\
\hline $14-20$ & $567 \quad(8.0)$ & (3.9) & \\
\hline $21-30$ & $(21.0)$ & $(4.2)$ & \\
\hline
\end{tabular}

rate of claims for HCPs after the schedule change. Before the schedule change, prescribers may have been inclined to prescribe HCPs because there were fewer restrictions in place. The movement of HCPs into DEA Schedule II may have increased prescriber awareness of their abuse potential and may have had an effect on decisions to prescribe HCPs.

Prescription opioid analgesic abuse and dependence, as well as the incidence of overdose death, has been on the rise for the past 2 decades. ${ }^{19}$ One analysis found that hydrocodone was among the top 10 substances named on death certificates in terms of number of times listed..$^{20}$ The HCP schedule change is one of many interventions aimed at addressing the prescription opioid abuse epidemic in recent years. For example, in October 2015, the White House announced public and private sector efforts to combat prescription drug abuse, including opioid prescriber training for more than 540,000 health care providers, expanded access to buprenorphine and naloxone, and increased provider registration with state prescription drug monitoring programs..$^{21}$ In February 2016, $\$ 1.1$ billion in funding was proposed to expand access to treatment, prevent overdose deaths, and increase community prevention strategies. ${ }^{22}$ Furthermore, in March 2016, the CDC published guidelines for the prescribing of opioids for chronic pain, targeting primary care clinicians. ${ }^{23}$

Two studies examined the use of HCPs and other analgesics after the HCP schedule change. One study, a retrospective analysis of 88,428 prescription orders at a large, academic, level one trauma center, examined analgesic use 6 months before and 6 months after the rescheduling of HCPs and found a decrease in HCP use but a concomitant increase in tramadol and codeine products. ${ }^{12}$ Meanwhile, our study found a decrease in HCP use, as well as use of the non-HCP analgesic comparators studied. A second study compared 
trends in analgesic exposures in Texas Poison Centers to assess whether there were changes in exposures to prescription analgesics and heroin in the 6 months after the HCP schedule change. ${ }^{24}$ This study found that there was a temporary decrease in the reported exposure to hydrocodone and increases in exposure to codeine, oxycodone, and tramadol and theorized that this may have reflected a shift in prescribing, changes in hydrocodone availability, or decreased hydrocodone diversion. ${ }^{24}$ Based on the literature, we anticipated a shift towards the use of less restricted opioid analgesics, such as Schedule III medications or tramadol, as alternative medications for the treatment of moderate to moderately severe pain. However, our study of a single Medicaid population shows that the decrease in the monthly rate of HCP claims was not accompanied by a concomitant increase in claims for non-HCP analgesics, regardless of whether those medications were in similarly or less-restrictive DEA Schedules.

Because we assumed that members who received chronic HCP therapy before the HCP schedule change would be likely to continue on those regimens, our study examined whether the schedule change affected prescribing of HCPs for members who had not filled HCP prescriptions within the preceding 6 months. After the HCP schedule change, we observed a significant decrease in the percentage of HCP claims for new start members as a function of all HCP claims. This decrease suggests that the HCP schedule change may have played a role in decreasing use in a portion of the HCP new start population; however, the degree to which the HCP schedule change played this role is unknown in light of other concurrent measures aimed at decreasing the use of opioid analgesics.

The average daily hydrocodone dose was similar between both study periods, reflecting that prescribers continued to write for the FDA-approved dosing for moderate to moderately severe pain (1-2 tablets every 4-6 hours as needed) with a shorter overall days supply. After the schedule change, there was an overall trend towards more conservative HCP prescribing as evidenced by the decrease in the average number of tablets per claim, shift towards shorter days supply per claim, and increase in the number of new start members who received only 1 HCP claim. These metrics are consistent with the DEA's intent for rescheduling HCPs as Schedule II substances to curb overprescribing.

Among the new start members, there was a demographic shift toward younger users after the HCP schedule change. This change may reflect a shift to more appropriate prescribing, since younger members tend to have more episodes of acute pain rather than chronic pain. More women than men in both periods received new HCP prescriptions. While it cannot be inferred that the overall use of opioid analgesics is higher in women than men in the general population, this is what was observed in this particular Medicaid population. The CDC has reported that deaths from prescription opioid overdoses have increased more substantially in women and that prescription drug overdose is an underrecognized and growing concern among women. ${ }^{17}$

One study evaluated IMS Health National Prescription Audit data and found that HCP prescriptions and total HCP tablets were declining in the years before the HCP schedule change, with a more accelerated decline after the HCP schedule change. ${ }^{11}$ National IMS data from 3 years before and 1 year after the HCP schedule change found that the number of dispensed HCP prescriptions and tablets decreased substantially after the HCP schedule change, with 26.3 million fewer HCP prescriptions and 1.1 billion fewer HCP tablets dispensed 1 year after the HCP schedule change. ${ }^{11}$ This study found that there were decreases in dispensed HCP prescriptions, with more pronounced decreases among primary care physicians and surgeons. ${ }^{11}$ Our findings are similar to this study in that we found a decrease in HCP use but did not find modest increases for non-HCP combination analgesics. Our study did not carve out non-HCP combination analgesics but included them in the other Schedule II medications comparator.

\section{Limitations}

Our findings are subject to several limitations. With the exception of tramadol, claims within comparator groups were not stratified by individual drug, so it was not possible to assess whether the use of a single analgesic changed in proportion to the overall use. Additionally, this study did not capture all HCP and non-HCP analgesic prescriptions filled from November 1, 2013, to September 30, 2015, since members could have paid out-ofpocket for prescriptions, which would not have been captured in the claims data.

Claims for the comparators decreased between December and February in both study periods (2013-2014 and 2014-2015). This observed decline in claims may be a result of either the change in the composition of Medicaid membership or other interventions that were not addressed by this study, such as an increased awareness of opioid safety on the part of prescribers and members.

The Medicaid plan employs formulary management strategies, such as prior authorization, that may affect the use of analgesics. During this study time period, the majority of generic HCPs were managed with prior authorization only if the total daily dose of acetaminophen in the combination product exceeded 4,000 mg. Select HCPs (hydrocodone/acetaminophen 5/300 mg, 7.5/300 mg, 10/300 mg, 10/750 mg; Maxidone, Stagesic, Vicodin, Vicodin ES, Vicodin HP) were also managed with prior authorization regardless of the dose prescribed because of the availability of less costly and therapeutically comparable analgesics; this may have affected HCP use to some extent because it could have affected how prescribers prescribe. However, since no new formulary management strategies were implemented during this study period, it is 
unlikely that these restrictions had any substantial effects on overall use.

\section{Conclusions}

This study's findings suggest that the HCP schedule change may have contributed to the decrease in claims for HCPs in a Medicaid population. After the HCP schedule change, there was a trend towards decreased HCP use among new starts. Future studies may investigate whether the HCP schedule change affected the incidence of opioid overdoses.

\section{Authors}

STEPHANIE TRAN, PharmD; PAVEL LAVITAS, PharmD, BCPS; KAREN STEVENS, PharmD; BONNIE C. GREENWOOD, PharmD, BCPS; CAROLINE J. ALPER, MD; MYLISSA PRICE, MPH, RPh; TASMINA HYDERY, PharmD, MBA, CGP; JENNIFER L. ARNOLD, MS; MITO TAKESHITA, PharmD; RACHEL BACON, PharmD; and JUSTIN P. PERISTERE, RPh, Clinical Pharmacy Services, University of Massachusetts Medical School, Shrewsbury. KAREN CLEMENTS, ScD, Center for Health Policy and Research, University of Massachusetts Medical School, Shrewsbury. KIMBERLY LENZ, PharmD, and PAUL L. JEFFREY, PharmD, Office of Clinical Affairs, University of Massachusetts Medical School, Quincy.

AUTHOR CORRESPONDENCE: Pavel Lavitas, PharmD, BCPS, Clinical Pharmacy Services, University of Massachusetts Medical School, 333 South St., Shrewsbury, MA 01545. Tel.: 774.455.3458;

E-mail:Pavel.Lavitas@umassmed.edu.

\section{DISCLOSURES}

No outside funding supported this study. The authors have nothing to disclose. Study concept and design were contributed by all authors except for Arnold and Clements. Tran, Arnold, and Clements took the lead in data collection, along with Peristere, and data interpretation was performed by all the authors, except Arnold. The manuscript was written primarily by Tran, along with Lavitas, Stevens, and Greenwood, and revised by all the authors except Arnold and Peristere.

A poster of this research project was presented at the Academy of Managed Care Pharmacy's 2016 Annual Meeting in San Francisco, California, April 2016.

\section{ACKNOWLEDGMENTS}

The authors thank Rose Mauro of Clinical Pharmacy Services at the University of Massachusetts Medical School for her assistance in gathering the data used in this report.

\section{REFERENCES}

1. Centers for Disease Control and Prevention. Prescription opioid overdose data. April 30, 2015. Available at: http://www.cdc.gov/drugoverdose/data/ overdose.html. Accessed March 24, 2017.

2. Centers for Disease Control and Prevention. Opioid painkiller prescribing. July 2014. Available at: http://www.cdc.gov/vitalsigns/opioid-prescribing/. Accessed March 24, 2017.

3. Volkow ND. America's addiction to opioids: heroin and prescription drug abuse. National Institute on Drug Abuse. May 14, 2014. Available at: https:// www.drugabuse.gov/about-nida/legislative-activities/testimony-to-congress/2015/americas-addiction-to-opioids-heroin-prescription-drug-abuse. Assessed March 24, 2017

4. Drug Enforcement Administration, Department of Justice. Schedules of controlled substances: rescheduling of hydrocodone combination products from schedule III to schedule II. Final rule. Fed Regist. 2014;79(163):49661-82.

5. Department of Justice, Drug Enforcement Administration. Controlled substance schedules. Available at: http://www.deadiversion.usdoj.gov/schedules/ Assessed March 24, 2017

6. Covey JR. Recent developments toward the safer use of opioids, with a focus on hydrocodone. Res Social Adm Pharm. 2015;11(6): 901-08.

7. Office of Diversion Control, Drug and Chemical Evaluation Section. Schedules of controlled substances: placement of hydrocodone combination products into schedule II background, data, and analysis: eight factors determinative of control and findings pursuant to 21 U.S.C. 812(b). Department of Justice, Drug Enforcement Administration. February 2014. Available at: http://www.regulations.gov/contentStreamer?documentId=DEA-2014-00050003\&disposition=attachment\&contentType=pdf. Assessed March 24, 2017.

8. Substance Abuse and Mental Health Services Administration. Highlights of the 2011 Drug Abuse Warning Network (DAWN) findings on drugrelated emergency department visits. The Dawn Report. February 22, 2013. Available at: http://www.samhsa.gov/data/sites/default/files/DAWN127/ DAWN127/sr127-DAWN-highlights.pdf. Accessed March 24, 2017.

9. Department of Justice, Drug Enforcement Administration. Schedules of Controlled Substances: Rescheduling of Hydrocodone Combination Products from Schedule III to Schedule II. 21 CFR Part 1308. August 22, 2014. Available at: http://www.deadiversion.usdoj.gov/fed_regs/rules/2014/ fr0822.htm. Accessed March 24, 2017.

10. Department of Justice, Drug Enforcement Administration. Prescriptions: Controlled Substances listed in Schedules III, IV, and V. 21 CFR Part 1306. March 31 2010. Available at: http://www.deadiversion.usdoj.gov/21cfr/ cfr/1306/1306_22.htm. Accessed March 24, 2017.

11. Jones CM, Lurie PG, Throckmorton DC. Effect of US drug enforcement administration's reschedule of hydrocodone combination analgesic products on opioid analgesic prescribing. JAMA Intern Med. 2016;176(3):399-402.

12. Schultz S, Chamberlain C, Vulcan M, Rana H, Patel B, Alexander JC. Analgesic utilization before and after rescheduling of hydrocodone in a large academic level 1 trauma center. J Opioid Manag. 2016;12(2):119-22.

13. Ghate SR, Haroutiunian S, Winslow R, McAdam-Marx C. Cost and comorbidities associated with opioid abuse in managed care and Medicaid patients in the United States: a comparison of two recently published studies. J Pain Palliat Care Pharmacother. 2010;24(3):251-58.

14. Coughlin TA, Long SK, Shen YC. Assessing access to care under Medicaid: evidence for the nation and thirteen states. Health Aff (Millwood). 2005;24(4):1073-83.

15. Adelmann PK. Mental and substance use disorders among Medicaid recipients: prevalence estimates from two national surveys. Adm Policy Ment Health. 2003;31(2):111-29.

16. Department of Justice, Drug Enforcement Administration. Schedules of Controlled Substances: Placement of Tramadol into Schedule IV. 21 CFR Part 1308. July 2, 2014. Available at: http://www.deadiversion.usdoj.gov/ fed_regs/rules/2014/fr0702.htm. Accessed March 24, 2017.

17. Centers for Disease Control and Prevention. Prescription painkiller overdoses: a growing epidemic, especially among women. July 2013. Available at: http://www.cdc.gov/vitalsigns/prescriptionpainkilleroverdoses/index.html. Accessed March 24, 2017.

18. McCarberg BH, Barkin RL. Long-acting opioids for chronic pain: pharmacotherapeutic opportunities to enhance compliance, quality of life, and analgesia. Am J Ther. 2001;8(3):181-86. 
19. Brady KT, McCauley JL, Back SE. Prescription opioid misuse, abuse, and treatment in the United States: an update. Am J Psychiatry. 2016;173(1):18-26.

20. Ossiander EM. Using textual cause-of-death data to study drug poisoning. Am J Epidemiol. 2014;179(7):884-94.

21. The White House Office of the Press Secretary. Fact sheet: Obama administration announces public and private sector efforts to address prescription drug abuse and heroin use. Press release. October 21, 2015. Available at: https://www.whitehouse.gov/the-press-office/2015/10/21/factsheet-obama-administration-announces-public-and-private-sector. Accessed March 24, 2017.
22. The White House Office of the Press Secretary. Fact sheet: President Obama proposes $\$ 1.1$ billion in new funding to address the prescription opioid abuse and heroin use epidemic. Press release. February 2, 2016. Available at: https://www.whitehouse.gov/the-press-office/2016/02/02/ president-obama-proposes-11-billion-new-funding-address-prescription. Accessed March 24, 2017.

23. Dowell D, Haegerich TM, Chou R. CDC guideline for prescribing opioids for chronic pain-United States, 2016. MMWR Recomm Rep. 2016;65(1):1-49. Available at: https://www.cdc.gov/mmwr/volumes/65/rr/rr650lel.htm. Accessed March 24, 2017.

24. Haynes A, Kleinschmidt K, Forrester MB, Young A. Trends in analgesic exposures reported to Texas Poison Centers following increased regulation of hydrocodone. Clin Toxicol (Phila). 2016;54(5):434-40. 
The Effect of a Federal Controlled Substance Act Schedule Change on

Hydrocodone Combination Products Claims in a Medicaid Population

\section{APPENDIX Comparator Groups, Analgesic Drugs, and Generic Sequence Numbers}

\begin{tabular}{|c|c|c|}
\hline Comparator Groups & Analgesics & Generic Sequence Numbers ${ }^{a}$ \\
\hline \multirow[t]{2}{*}{$\mathrm{HCPs}$} & Hydrocodone/acetaminophen & $004201,030623,047430,047431,053582,060338,060533$ \\
\hline & Hydrocodone/ibuprofen & 034068,054674 \\
\hline \multirow[t]{13}{*}{ Other Schedule II analgesics } & Buprenorphine patches & $059589,059590,059591,071432$ \\
\hline & Codeine & $004185,004186,004187$ \\
\hline & Fentanyl & $015880,015881,015882,015883,059102$ \\
\hline & Hydromorphone & $004110,004112,015190,016156,016847,069890$ \\
\hline & Levorphanol & 004228 \\
\hline & Meperidine & 004053 \\
\hline & Methadone & $004238,004239,004240,004242$ \\
\hline & Morphine & $\begin{array}{l}004076,004087,004089,004090,004091,004092,004096,004097,011886,011887, \\
011886,011887,060355,061748,016522,031465,060356,060357\end{array}$ \\
\hline & Oxycodone & $\begin{array}{l}004224,004225,013467,015065,024507,045298,046474,046475,072862,072863, \\
072864,072865,072866,072867,072868\end{array}$ \\
\hline & Oxycodone/acetaminophen & $004222,013998,048976,048977$ \\
\hline & Oxycodone/aspirin & 060638 \\
\hline & Oxymorphone & $061086,061091,061094,063784,070397,070400$ \\
\hline & Tapentadol & $065319,065321,067267$ \\
\hline Schedule III analgesics & Acetaminophen/codeine & $004163,004165,004169,045155$ \\
\hline Tramadol & Tramadol & $023139,043536,043537,048456,060274$ \\
\hline \multirow[t]{3}{*}{ Nonscheduled analgesics } & NSAIDs & $\begin{array}{l}004285,004438,004439,004443,008336,008337,008338,008340,008341,008346, \\
008348,008349,008350,008354,008357,008358,008359,008360,008361,008362, \\
008363,008365,008366,008367,008370,008371,008372,008373,008374,008379, \\
008380,011933,012080,013556,015960,015961,016404,016406,016574,016575, \\
017204,018293,018435,018436,020175,021380,021980,022530,023855,027368, \\
029156,029157,031613,039500,041285,041286,050832,051971,060179,062001, \\
062176,066844,071910\end{array}$ \\
\hline & Acetaminophen & $\begin{array}{l}004473,004475,004477,004481,004484,004485,004489,004490,004493,004494, \\
016943,016947,022123,065756,068842\end{array}$ \\
\hline & Lidocaine patches & 043256 \\
\hline
\end{tabular}

${ }^{a}$ Generic Sequence Numbers are not all inclusive; those that did not yield claims were not reported in this table.

$\mathrm{HCP}=$ hydrocodone combination product; NSAIDs = nonsteroidal anti-inflammatory drugs. 